\title{
Entrelacs
}

ENTRELACS Cinéma et audiovisuel

18 | 2021

Laurent Roth, cinéaste

\section{Le Pays fantôme. Lettre au festival Doc en courts}

\section{Laurent Roth}

\section{OpenEdition}

Journals

Édition électronique

URL : https://journals.openedition.org/entrelacs/6154

DOI : 10.4000/entrelacs.6154

ISSN : 2261-5482

Éditeur

Éditions Téraèdre

\section{Référence électronique}

Laurent Roth, «Le Pays fantôme. Lettre au festival Doc en courts », Entrelacs [En ligne], 18| 2021, mis en ligne le 13 décembre 2021, consulté le 15 décembre 2021. URL : http://journals.openedition.org/ entrelacs/6154; DOI : https://doi.org/10.4000/entrelacs.6154

Ce document a été généré automatiquement le 15 décembre 2021.

Tous droits réservés 


\section{Le Pays fantôme. Lettre au festival Doc en courts}

\section{Laurent Roth}

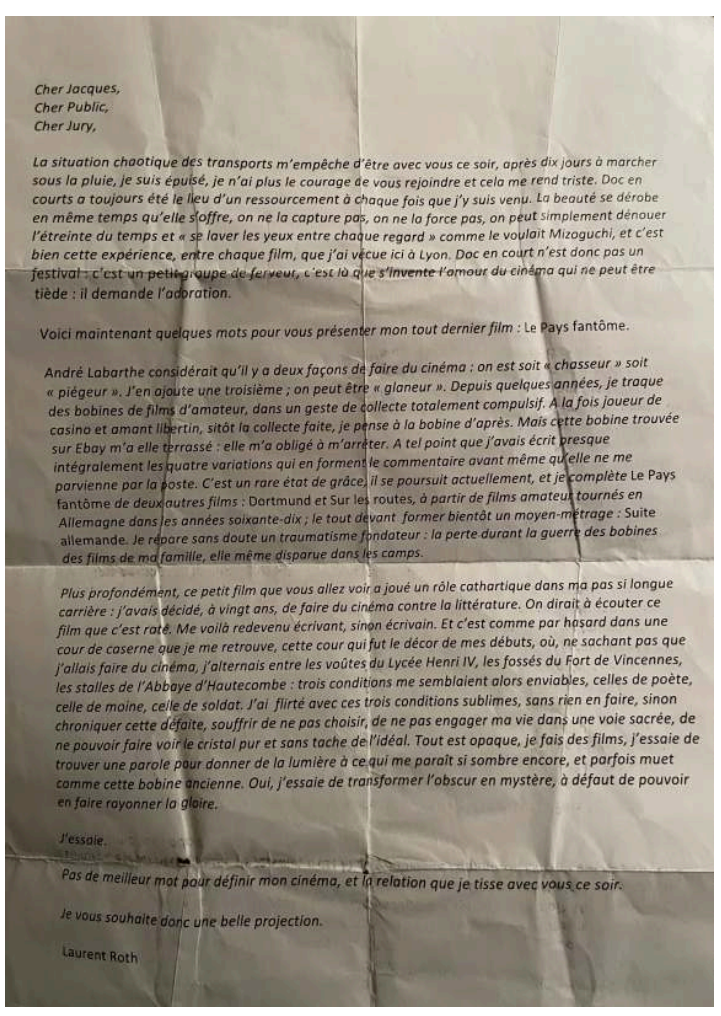

Crédit image : Jacques Gerstenkorn.

Villiers-le-Bâcle, le 19 décembre 2019.

André Labarthe considérait qu'il y a deux façons de faire du cinéma: on est soit « chasseur » soit « piégeur ». J'en ajoute une troisième ; on peut être " glaneur ». Depuis quelques années, je traque des bobines de films d'amateur, dans un geste de collecte totalement compulsif. À la fois joueur de casino et amant libertin, sitôt la collecte faite, je pense à la bobine d'après. Mais cette bobine trouvée sur eBay m'a elle terrassé : elle 
m'a obligé à m'arrêter. À tel point que j'avais écrit presque intégralement les quatre variations qui en forment le commentaire avant même qu'elle ne me parvienne par la poste. C'est un rare état de grâce, il se poursuit actuellement, et je complète Le Pays fantôme de deux autres films: Dortmund et Sur les routes, à partir de films amateur tournés en Allemagne dans les années soixante-dix; le tout devant former bientôt un moyen-métrage: Suite allemande. Je répare sans doute un traumatisme fondateur: la perte durant la guerre des bobines des films de ma famille, elle même disparue dans les camps.

Plus profondément, ce petit film que vous allez voir a joué un rôle cathartique dans ma pas si longue carrière: j'avais décidé, à vingt ans, de faire du cinéma contre la littérature. On dirait à écouter ce film que c'est raté. Me voilà redevenu écrivant, sinon écrivain. Et c'est comme par hasard dans une cour de caserne que je me retrouve, cette cour qui fut le décor de mes débuts, où, ne sachant pas que j’allais faire du cinéma, j'alternais entre les voûtes du Lycée Henri IV, les fossés du Fort de Vincennes, les stalles de l'Abbaye d'Hautecombe: trois conditions me semblaient alors enviables, celles de poète, celle de moine, celle de soldat. J'ai flirté avec ces trois conditions sublimes, sans rien en faire, sinon chroniquer cette défaite, souffrir de ne pas choisir, de ne pas engager ma vie dans une voie sacrée, de ne pouvoir faire voir le cristal pur et sans tache de l'idéal. Tout est opaque, je fais des films, j'essaie de trouver une parole pour donner de la lumière à ce qui me paraît si sombre encore, et parfois muet comme cette bobine ancienne. Oui, j'essaie de transformer l'obscur en mystère, à défaut de pouvoir en faire rayonner la gloire.

J'essaie.

\section{RÉSUMÉS}

Faute de pouvoir se rendre à Lyon du fait de la grève des transports pour y présenter Le Pays fantôme dans le cadre du festival Doc en courts en 2019, Laurent Roth a adressé, en guise de présentation au public, une lettre que nous reproduisons ici. Le Pays fantôme s'est vu décerner lors de cette 19 e édition une mention spéciale du jury du Grand Prix.

As he was unable to travel to Lyon due to the transport strike to present Le Pays fantôme at the Doc en courts festival in 2019, Laurent Roth sent the following letter to the public by way of introduction. Le Pays fantôme was awarded a special mention by the Grand Prix jury at this 19th edition. 